\title{
NORMATIVISMO LINGUÍSTICO EM REDES SOCIAIS DIGITAIS: UMA ANÁLISE DA FANPAGE LÍNGUA PORTUGUESA NO FACEBOOK
}

\author{
LINGUISTIC NORMATIVISM IN DIGITAL SOCIAL \\ NETWORKING: AN ANALYSIS OF LÍNGUA PORTUGUESA \\ FANPAGE ON THE FACEBOOK
} Benedito Gomes Bezerra*
Renato Lira Pimentel

\section{RESUMO}

As práticas discursivas instauradas pelas redes sociais digitais e mediadas por sites como o Facebook recebem uma grande adesão de adolescentes e jovens. Por outro lado, sofrem considerável estigma por parte de instâncias reguladoras dos usos da língua portuguesa. A escrita no ambiente digital torna-se um mecanismo de acentuada autoexposição dos usuários, ocasionando juízos de valor sobre usos "certos" e "errados" da língua. Nesse sentido, certa quantidade de páginas (fanpages) do Facebook, cujas postagens são "curtidas", comentadas e eventualmente "compartilhadas" nas "linhas do tempo" dos usuários, vêm se constituindo em instâncias de ensino informal dos usos da língua tidos como melhores ou corretos, de forma paralela à instituição escolar. Diante disso, torna-se necessário compreender o significado dessas práticas discursivas no ambiente virtual: quais são as faces desse normativismo e que imaginário instaura ou reproduz sobre a língua portuguesa e seus usos, especialmente os que se verificam na interação pelas próprias redes sociais? $\mathrm{O}$ presente trabalho, amparado nos estudos contemporâneos sobre redes sociais digitais (RECUERO, 2009), por um lado, e nas noções sociolinguísticas de norma (FARACO, 2008), variação e preconceito linguístico (BAGNO, 2007, 2011, 2013), por outro, tem como objetivo central investigar facetas do normativismo linguístico veiculado através de fanpages como a página Língua Portuguesa, ambientada no Facebook, em sua relação com as práticas de escrita em ambiente digital. O estudo aborda, em caráter exploratório e qualitativo, postagens efetuadas na referida fanpage, incluindo na análise tanto o texto/imagem que compõe a postagem como os comentários dos usuários.

Palavras-chave: Normativismo linguístico; preconceito linguístico; fanpages.

\section{ABSTRACT}

Discursive practices brought by digital social networking and mediated by sites like Facebook receive a large membership of young people. On the other hand, they suffer considerable stigma by regulators of the Portuguese language uses. Writing in digital settings becomes a

\footnotetext{
* Universidade de Pernambuco, Santo Amaro (PE), Brasil. beneditobezerra@gmail.com

** Universidade Federal de Pernambuco, Recife (PE), Brasil. lira.pimentel88@yahoo.com.br
} 
sharp auto exposure mechanism for users, resulting in judgments about "right" and "wrong" usages of language. In this sense, a certain amount of fan pages of Facebook, whose posts are "liked", commented and eventually "shared" in the users "timelines", have constituted themselves as informal learning environments for language uses regarded as best or correct, in parallel to the schooling institutions. Therefore, it is necessary to understand the meaning of these discursive practices in the virtual environment: what are this normativism faces and what imaginary it establishes or reproduces on the Portuguese language and its use, especially those that occur in the interactions in the very social networks? This research was based on contemporary studies on digital social networking (RECUERO, 2009), on the one hand, and on the sociolinguistic notions of standard (FARACO, 2008), variation and linguistic discrimination (BAGNO, 2007, 2011, 2013), on the other. Its main objective is to investigate facets of linguistic normativism conveyed through fan pages like Lingua Portuguesa in the Facebook, in its relation to the writing practices in the digital environment. The study focuses, in an exploratory and qualitative way, on postings made in that fan page, performing the analysis of both text and image that constitute the post and of the user's comments.

Keywords: Linguistic normativism; linguistic prejudice; fan pages.

\section{INTRODUÇÃO}

As redes sociais digitais, que se constituem e adquirem visibilidade pela instrumentalidade de sites e aplicativos como o Facebook, promovem a circulação de textos em diferentes gêneros mais ou menos típicos do meio digital, uma vez que tais textos em geral se constituem a partir da hibridização de gêneros já existentes nas mídias convencionais, mas, por vezes, também manifestam a pretensão de configurar práticas discursivas inusitadas. Muitas dessas práticas discursivas, por um lado, recebem uma grande adesão de adolescentes e jovens em idade escolar e, por outro lado, sofrem considerável estigma por parte de instâncias reguladoras dos usos da língua portuguesa. A escrita no ambiente digital, mais do que a oralidade na interação face a face, torna-se um mecanismo de autoexposição dos usuários, ocasionando juízos de valor sobre usos "certos" e "errados" da língua.

Nesse sentido, é possível constatar, no dia a dia da navegação pela World Wide Web, que uma quantidade razoável de páginas (fanpages) e grupos do Facebook, ao lado das postagens nas timelines dos usuários em geral, vêm se erigindo como instâncias de ensino informal dos usos da língua tidos como os melhores ou os (mais) corretos, de forma paralela à instituição escolar. Daí a importância e a necessidade de se compreender o significado dessas novas práticas discursivas no cotidiano dos usuários da língua em geral e dos estudantes em particular, além de se buscar meios de estabelecer pontes entre elas e as práticas propostas pela instituição escolar.

Mais especificamente, urge compreender, entre as práticas discursivas com que se envolve o usuário de redes sociais digitais, aquelas voltadas para a "defesa" 
da língua portuguesa, constituídas provavelmente como reação à interpretação de que esta vem sendo "assassinada" pelos adolescentes e jovens em suas práticas diárias de escrita na web. Compreender essas práticas implica confrontá-las com concepções acadêmicas bem estabelecidas sobre o que significa usar uma língua, bem como examinar a pertinência de noções como "decadência" ou "assassinato" de uma língua pelos seus próprios falantes.

Parece claro que, apesar dos esclarecimentos trazidos por pesquisas recentes, prevalece ainda um grande descompasso entre o discurso acadêmico e o discurso do senso comum, este reforçado muitas vezes por olhares prescritivistas sobre as práticas discursivas, no tocante à natureza da interação que se dá no ambiente da Internet. $\mathrm{O}$ discurso que alcança e impressiona o senso comum é o discurso alarmista que chama a atenção para o pretenso dano que certos usos da linguagem na Internet acarretariam sobre a escrita de adolescentes e jovens em contextos formais. $\mathrm{O}$ discurso acadêmico, ainda que embasado em pesquisa, não consegue alterar essa realidade, alimentada, aliás, até por muitos professores de língua portuguesa formados e em formação, como podemos verificar no dia a dia de nossa atuação em cursos de graduação e pós-graduação em Letras.

Diante dessas considerações, o objetivo deste trabalho é discutir concepções normativistas de língua expressas através da fanpage Língua Portuguesa do site de redes sociais Facebook, considerando sua relação com as práticas de escrita realizadas em ambiente digital. Adicionalmente, procuramos refletir sobre o normativismo linguístico no Facebook do ponto de vista de suas implicações para o ensino de língua.

Em vista de seus objetivos, o trabalho se organiza da seguinte forma: em primeiro lugar, apresentamos as principais noções que orientam o estudo no que diz respeito às redes sociais e sua relação com sites como o Facebook, além de esclarecer o que são fanpages no interior deste último. Em seguida, discutimos os conceitos sociolinguísticos de norma, variação e preconceito que fundamentam nosso olhar para as práticas de escrita tais como discutidas na fanpage Língua Portuguesa. Por último, apresentamos os procedimentos metodológicos adotados, seguidos de sua aplicação na análise de postagens e comentários colhidos na referida página virtual do Facebook, antes de concluir o trabalho com as nossas considerações finais.

\section{O FACEBOOK E AS REDES SOCIAIS DIGITAIS}

Em estudos recentes, diversos autores têm se dedicado a uma variedade de temáticas relacionadas com o Facebook. Por exemplo, Pimentel (2014) caracteriza 
e discute a colônia de gêneros que se constituem em torno do site; também no Facebook, Lima-Neto (2014) analisa o fenômeno da emergência de gêneros, enquanto Barros (2015) investiga os processos argumentativos e a escrita colaborativa em comentários nas linhas do tempo de usuários. No que tange a pesquisas voltadas para os usos variáveis da língua, de inspiração sociolinguística, há uma diversidade de estudos voltados para o internetês, a "linguagem da Internet" ${ }^{\prime \prime}$, especialmente fazendo comparação entre a escrita informal, recreativa, em ambiente virtual e a escrita em situações convencionais ou formais, por exemplo, em contexto escolar (cf. BISOGNIN, 2009; MELO; BEZERRA, 2011). A presente pesquisa se alinha com os poucos estudos acadêmicos voltados para instâncias de normatização da língua nas redes sociais digitais e particularmente no Facebook, alguns dos quais também elegeram a página Lingua Portuguesa como foco de investigação, a exemplo de Pires e Pinto (2013) e Santos e Romano (2015).

Em um contexto mais amplo, uma rápida pesquisa no Google resulta em uma quantidade imensa de páginas, imagens e vídeos que exibem, enumeram, discutem, advertem contra e sobretudo ridicularizam os "erros de português mais comuns/ mais bizarros nas redes sociais", mostrando que estas têm sido tratadas como uma espécie de bode expiatório para todo tipo de uso não padrão da língua, mesmo quando os "erros" em questão claramente têm sua origem fora das mídias digitais ou quando subsistem independentemente delas.

Mas o que são mesmo as tão faladas redes sociais e como o Facebook se situa em relação a elas? Neste trabalho, entendemos redes sociais na perspectiva apresentada por Recuero (2009, p. 24), como uma "metáfora para observar os padrões de conexão de um grupo social, a partir das conexões estabelecidas entre os diversos atores". Uma rede social, portanto, é um tipo de estrutura social que conecta pessoas, instituições ou grupos, tendo, a nosso ver, a linguagem como o principal mecanismo para essa conexão. Redes sociais existiam e eventualmente existem à parte da Internet, de modo que se torna necessário especificar que aqui tratamos de uma espécie particular de redes sociais: aquelas que se formam, se mantêm e se propagam pela instrumentalidade das novas Tecnologias de Informação e Comunicação, em especial, através da Internet.

Essas redes, às quais Recuero (2009) se refere como "redes sociais na Internet", nós as denominamos "redes sociais digitais", entendendo-as como redes de pessoas que se formam mediante a instrumentalidade de artefatos tecnológicos como os computadores, os dispositivos móveis de comunicação (smartphones, tablets),

1 A propósito disso, ver Bezerra (2013). 
a Internet, os sites, os aplicativos para dispositivos móveis. Tais redes atualmente existem em quantidade inumerável e cada pessoa participa simultaneamente de várias delas, inclusive pela instrumentalidade de um mesmo site ou aplicativo.

Assim, fica claro que, ao contrário do senso comum, não consideramos o Facebook como uma rede social, mas sim, novamente de acordo com Recuero (2009), como um "site de redes sociais". Dessa forma, para fins de clareza terminológica, ressaltamos que o site Facebook não é uma rede social por dois motivos: (1) uma rede é constituída por pessoas e não por um artefato tecnológico; e (2) as redes agregadas a sites como o Facebook são plurais, e não únicas. Noutras palavras, o Facebook é um site através do qual múltiplas redes sociais se formam e se desenvolvem. Cada usuário, ao longo de sua atividade no Facebook, acaba participando de diversas redes sociais, cada uma delas podendo definir focos específicos como, entre várias outras possibilidades, relacionamentos pessoais, discussões políticas ou militâncias sociais diversas, como a militância pela "divulgação da Língua Portuguesa", a exemplo da fanpage analisada por este trabalho.

Assim, por exemplo, se um usuário possui 500 "amigos" em sua página do Facebook, apenas parte deles possivelmente se engajará em discussões sobre a língua. É mais provável que essa discussão seja motivo para a constituição de uma rede à parte, que será constituída tanto por "amigos" do usuário como por pessoas sem nenhum outro relacionamento com ele. Haverá pessoas que se relacionarão com o usuário principalmente em torno de temas de afinidade profissional ou esportiva, enquanto outro grupo se concentrará em interações mais pessoais e assim por diante, de forma que um mesmo usuário interage com e participa de variáveis redes sociais. ${ }^{2}$

Entre os recursos que o Facebook disponibiliza para a formação, interação e propagação das redes sociais, destacam-se asfanpages ("páginas de fã" ou simplesmente "páginas do Facebook"), que são interfaces específicas para a divulgação de empresas, marcas ou causas diversas. Nos termos da Central de Ajuda do Facebook, as fanpages "servem para as empresas, marcas e organizações compartilharem suas histórias e se conectarem com as pessoas". Dito de outra forma, as fanpages são dispositivos oferecidos pelo Facebook para facilitar a formação de redes sociais em torno de empresas, marcas, organizações e causas diversas. Essas causas, particularmente, nem sempre são representadas por organizações, mas sim por pessoas, como é o caso da página Lingua Portuguesa.

2 Nesse aspecto, essas redes eventualmente poderão se aproximar bastante do que Swales (1990, 2009) chamou de "comunidades discursivas". 
O usuário se torna "seguidor" de uma fanpage ao "curtir" essa página, ação que funciona como uma espécie de filiação à rede social/comunidade afinada com aquela proposta. No caso da fanpage Língua Portuguesa, como mencionado, informa-se que a proposta é a "divulgação da língua portuguesa". Na descrição longa constante da aba "sobre", a página é apresentada como "um espaço para os admiradores da LÍNGUA PORTUGUESA" e o usuário é convidado a juntar-se a "nós" (portanto, formar, juntamente com a proprietária da página, uma rede social dedicada à proposta) na tarefa de "cuidar" do idioma falando e escrevendo "corretamente". Concretamente, o usuário pode juntar-se à rede comentando as postagens da responsável pela fanpage. Nesses comentários, poderá interagir com ela e com os demais usuários, e eventualmente dar sugestões de novas postagens.

Vejamos a seguir, no que diz respeito à língua e à normatividade linguística, os conceitos teóricos que orientarão nosso olhar para as postagens e comentários sobre a língua na página em questão.

\section{NORMA LINGUÍSTICA E HETEROGENEIDADE DA LÍNGUA}

O conceito de norma que orienta este estudo se baseia em autores como Faraco (2008) e Bagno $(2007,2011,2013)$, entre outros. Esse conceito implica uma concepção de língua como heterogênea e variável, aberta a uma diversidade de usos além dos estabelecidos pela Gramática Normativa.

Nessa concepção, negamos que as línguas se organizem de uma maneira uniforme, fazendo com que seus usos orais ou escritos possam ser caracterizados alternativamente como "certos" ou "errados". Antes, toda língua se constitui como um conjunto de variedades dotadas de diferenças recíprocas, cada uma delas podendo ser utilizada de acordo com os contextos sociais de interação. Pensamos, concordando com Bagno (2011), que seja impossível separar dentro da língua "o que pertence à estrutura ou ao sistema linguístico [...] e o que é constructo cultural, social, político, ideológico" (BAGNO, 2011, p. 356). Assim, pelo menos no caso das sociedades letradas, historicamente, cada língua acaba tendo uma de suas variedades definida como preferível em relação às demais, especialmente em contextos formais de interação.

Essa variedade da língua, eleita de forma relativamente inconsciente por critérios culturais, políticos, econômicos e ideológicos, e não por qualidades linguísticas intrinsecamente superiores às qualidades das demais variedades, passa a regular oficialmente as práticas comunicativas na oralidade e na escrita. Passa 
também a ser valorizada como superior às demais variedades, sendo eleita como modelo para o ensino e sendo exigida nas situações formais de uso, como nos contextos profissionais e acadêmico, por exemplo. Em uma palavra, essa variedade de uso da língua se torna padrão e adquire grande prestígio social, sendo capaz de transferir, em princípio, esse prestígio para os seus usuários. O conceito de norma tem a ver com esse processo e essa maneira de lidar com as variedades empíricas ou idealizadas da língua. Na língua portuguesa, como virtualmente em qualquer língua natural, convivem diversas normas linguísticas, ainda que socialmente se dê visibilidade apenas à chamada norma padrão.

De acordo com Ilari e Basso (2006), a busca de uma norma para o português brasileiro foi, ao longo da história nacional, objeto de preocupação de diversos autores com propósitos muito diferentes, assumindo três características igualmente diversificadas. Nesse sentido, em nome do conceito de norma, procurou-se realizar diferentes objetivos, como mostramos a seguir:

(1) A definição de uma norma literária propriamente brasileira, livre das imposições oriundas de Portugal. No século XIX, um autor brasileiro, do período romântico, que muito se empenhou em defender "o direito de legislar sobre a língua que falamos" foi o cearense José de Alencar.

(2) A elaboração de uma norma para o português escrito culto, representada pela polêmica em torno da construção do texto do Código Civil entre os anos de 1902 e 1907, envolvendo o político Rui Barbosa e o gramático Ernesto Carneiro Ribeiro. A referida polêmica não versava sobre o conteúdo do Código, mas sobre aspectos de sua redação, em que cada um dos lados defendia sua versão como sendo a "certa" e a do outro, como "errada".

(3) A busca de uma norma fonética para o português brasileiro, representada por congressos que na primeira metade do século XX procuravam regulamentar a pronúncia da língua para permitir o seu uso no canto lírico e no teatro. A ideia desses congressistas, entre os quais se encontravam figuras ilustres como os escritores Mário de Andrade e Manuel Bandeira, o filólogo Antônio Houaiss e o gramático Celso Cunha, tendia ora para escolher o sotaque de uma determinada região (geralmente o Rio de Janeiro) como norma para o país, ora para fazer uma média entre os sotaques das diversas regiões.

Entre todas essas modalidades de norma, a que mais exerceu e exerce influência sobre a sociedade brasileira provavelmente é a noção de norma da 
língua escrita, a qual se afastou consideravelmente da linguagem popular em geral, principalmente por se basear nos usos literários e no português europeu.

No entanto, como demonstra Faraco (2008), o conceito de norma surgiu nos estudos linguísticos exatamente com a intenção de captar a heterogeneidade da língua, e não como meio de eleger e perpetuar uma variedade linguística como legítima em detrimento das demais. $\mathrm{O}$ autor lembra que, tal como adotada nos estudos da linguagem, o conceito de norma deriva do linguista romeno Eugenio Coseriu, que ainda no início da década de 1950 definia norma como "cada um dos diferentes modos sociais de realizar os grandes esquemas de relações do sistema", superando assim a dicotomia saussureana entre língua e fala.

Norma linguística, portanto, não se refere ao que é possível dizer numa língua, e sim ao que efetivamente se diz num determinado grupo ou comunidades de falantes. Norma é o conjunto de usos "normais" para uma determinada comunidade linguística. O mesmo sistema linguístico (língua) pode dar origens a diferentes normas linguísticas, de acordo com os diferentes grupos sociais formados por seus falantes.

Segundo Faraco $(2008$, p. 37), podemos definir norma como "determinado conjunto de fenômenos linguísticos (fonológicos, morfológicos, sintáticos e lexicais) que são correntes, costumeiros, habituais numa dada comunidade de fala". Percebemos, portanto, que norma aqui não é sinônimo de regra ou regulamento, mas de "normalidade", de uso costumeiro numa determinada comunidade de fala.

Um aspecto fundamental no conceito de norma linguística é o de que toda norma é organizada e coerente. Não existem normas linguísticas caóticas, sem regras ou sem gramática. Uma concepção de norma, portanto, compreende apenas conjuntos de usos que são possíveis na estrutura da língua e no interior dos diversos grupos sociais. Isso obviamente se aplica também aos usos não padrão verificados na Internet e fora dela.

O conceito de norma é, assim, plural. $\mathrm{O}$ que existe são normas e não uma norma única de uso da língua. Cada comunidade, virtual ou não, possui suas próprias normas. E o conjunto dessas normas confere à língua portuguesa a sua heterogeneidade e diversidade. Dessa forma, como destaca Faraco (2008, p. 46), pares dicotômicos como português culto x português popular ou português padrão x português não padrão são incapazes de descrever a complexidade dos fatos linguísticos do português brasileiro. São apenas simplificações usadas para descrever o fenômeno linguístico de forma geral. Igualmente inútil e incorreto é identificar o "português formal" com a escrita e o "português informal" com a fala.

Seguindo esse pensamento, além de plural, o conceito de norma é também problemático. A expressão "norma culta", por exemplo, pode ser inadequada e 
ambígua por sugerir que as demais normas sejam "incultas", além de absolutizar e uniformizar o adjetivo "culto". A própria noção de "norma culta" também é plural necessariamente. Não existe uma só norma culta, mas diversas normas cultas. $\mathrm{Na}$ opinião de Faraco $(2008$, p. 23), a confusão reinante sobre o termo é resultado do fato de que ele "pulou os muros da universidade e se tornou muito frequente no discurso da mídia e da escola". Assim, a confusão mais frequente é tomar norma culta como sinônimo de norma padrão. Outro problema é entender norma culta como a norma prescrita por gramáticas e dicionários, que deveriam se chamar, conforme Faraco (2008), de norma gramatical, até considerando que as pessoas cultas fazem uso da língua muitas vezes de forma não abonada por essa norma.

Quando se trata dos usos da língua, o discurso purista predomina na sociedade brasileira. Esse discurso impõe uma série de restrições aos usos legítimos dos falantes em nome da "norma culta". Por isso, Faraco (2008) ironicamente rotula essa atitude como "norma curta". A norma "curta" é opressiva por se basear em proibições e restrições sobre o que se pode falar e o que não se pode falar. Em geral, trata-se de discutir detalhes insignificantes como se fossem questões extremamente centrais e determinantes para o futuro da língua e de seus falantes.

A "norma culta", portanto, se torna norma "curta" quando se apresenta como uma norma "que apequena a língua, que encurta sua riqueza, que não percebe (por conveniência ou ignorância?) que o uso culto tem abundância de formas alternativas e não se reduz a preceitos estreitos e rígidos" (FARACO, 2008, p. 66). O conceito, embora irônico, serve bem para chamar a atenção para a miopia de uma concepção de norma que reduz a língua a um padrão artificial, idealizado, que se tenta impor a todos os falantes como o único uso possível.

A norma curta, entendida como "a miséria da gramática" (FARACO, 2008), representa um conjunto de preceitos extremamente rigorosos e sem base nas boas gramáticas normativas e nos bons dicionários da língua. Segundo Faraco (2008, p. 95), essa norma curta é "o reino da inflexibilidade, das afirmações categóricas, do certo e do errado tomados em sentido absoluto. A norma curta é o mundo das condenações raivosas, das rabulices gramaticais". A norma "curta" relaciona-se diretamente com o conceito de norma padrão.

A tentativa de construção de um padrão linguístico para as línguas resulta, em parte, do próprio processo histórico de constituição da autonomia e independência dos Estados contemporâneos. A adoção de uma norma padrão ${ }^{3}$ cumpre a função

\footnotetext{
3 Para uma discussão mais profunda em relação a padrão e padronização, no que se refere à norma, ver Milroy (2011)
} 
de desautorizar aspirações regionais por independência, negando aos grupos dissidentes a legitimidade do ponto de vista da diversidade linguística. Em todos os casos, a norma padrão se baseia numa variedade linguística tomada como ideal, mas geralmente abstraída dos usos das elites dominantes. Desde o início, a norma padrão se afasta dos usos reais e se codifica em gramáticas e dicionários da língua. Isso acontece também quando se refere a usos, ou os toma da literatura, como se esta fosse modelo para a linguagem cotidiana, ou de usos arcaicos ou adotados do português europeu.

O grande objetivo do surgimento da norma padrão brasileira foi combater a linguagem popular (esse foco se mantém claramente hoje), entendida pejorativamente como "língua de índios", "língua de negros" ou "língua de matutos". Na concepção de Faraco (2008), os usuários do português brasileiro não precisam mais, se é que já precisaram, de uma norma padrão, pois as variedades cultas não correm nenhum risco de desaparecimento ou descaracterização. Segundo Bagno (2007), deveríamos inclusive evitar até mesmo o termo norma culta, preferindo falar de variedades prestigiadas (que normalmente são variedades ou normas cultas) e de variedades estigmatizadas (em geral, associadas às classes populares, a faixas etárias como a dos adolescentes ou a grupos sociais como os caipiras e os analfabetos). A existência de variedades estigmatizadas se deve exatamente, entre outros fatores, à ação da norma "curta", que relega as variedades divergentes ao desprezo e à desvalorização social.

Bagno (2013) destaca ainda que as noções de norma culta e norma padrão são intrinsecamente questões ideológicas. Para o autor, há um complexo jogo de relações nunca igualitárias entre língua e sociedade, pois, embora as variedades linguísticas tenham uma equivalência de função, elas possuem valores sociais diferentes.

O estudioso também fez o seu próprio trocadilho com o termo norma culta (BAGNO, 2003), usando a expressão norma "oculta" para aprofundar o estudo das relações entre língua e poder no Brasil e avança para a afirmação de que o preconceito linguístico na sociedade brasileira é, na verdade, um profundo e entranhado preconceito social. A norma culta é na verdade uma norma "oculta", inclusive por ocultar esse jogo social de discriminação e dominação por meio dos usos linguísticos. Bagno (2011, p. 367) ainda afirma que o que existe, quando se discutem termos como "variedade padrão", "dialeto padrão" ou "língua padrão", "é uma norma padrão língua materna de ninguém, língua paterna por excelência, língua da lei, uma norma no sentido mais jurídico do termo". 
Neste trabalho, procuramos discutir de que maneiras a noção de norma se manifesta, na fanpage Língua Portuguesa do Facebook, como normativismo, entendido como a fixação em uma concepção de língua reduzida a uma norma padrão que é sinônimo de norma curta e de norma oculta, pelo reducionismo em torno dos fenômenos linguísticos e pela dissimulação dos jogos ideológicos que a sustentam.

\section{A FANPAGE LÍNGUA PORTUGUESA: REPERCUSSÕES NOS ESTUDOS DA LINGUAGEM}

A "defesa" da língua é um empreendimento sempre abraçado por pessoas que se decidem a (re)agir contra usos linguísticos que a seu ver ameaçam "assassinar", "deturpar" ou ainda fazer "regredir" o idioma. No âmbito da Internet, essas iniciativas corporificam-se em sites e blogs e aplicativos de diversas naturezas. Para mencionar apenas o Facebook, aí é possível localizar uma diversidade de "grupos" e "páginas" que se dedicam a fornecer dicas de usos "corretos" da língua ou ainda a denunciar, corrigir e ridicularizar "erros" frequentes nas redes sociais, no ENEM e em diversas outras instâncias de uso da linguagem.

Criada em agosto de 2011, a fanpage Língua Portuguesa chama a atenção pela sua popularidade, aferida pela quantidade de "curtidas" que a página apresenta: quase um milhão e quatrocentas mil até meados de janeiro de 2016. Parece ser, de longe, a página mais popular nessa categoria. Pode-se afirmar, assim, que as ideias ali veiculadas certamente terão um impacto em construir e/ou manter um determinado imaginário sobre a língua portuguesa.

Em sua descrição (ver Figura 1), a página é apresentada como "dedicada à divulgação da Língua Portuguesa" e como um "espaço para os admiradores" dessa língua. Presume-se que, em sua concepção de língua, a idealizadora da página acredita na necessidade de "divulgar" a língua para os seus próprios falantes, uma vez que em princípio somente estes serão capazes de ler os conteúdos ali expostos. Além disso, parece ser um pressuposto de que entre os falantes da língua portuguesa há os que são os seus admiradores e outros que não o são. Que não se trata de divulgar a língua portuguesa para falantes de outras línguas, infere-se pelo convite para que o usuário "cuide do seu idioma". A partir dessa descrição, percebe-se que a língua é de fato reduzida a um ideal normativo e, consequentemente, vista como necessitada de "cuidado", que seria evidenciado por falar e escrever "corretamente". 


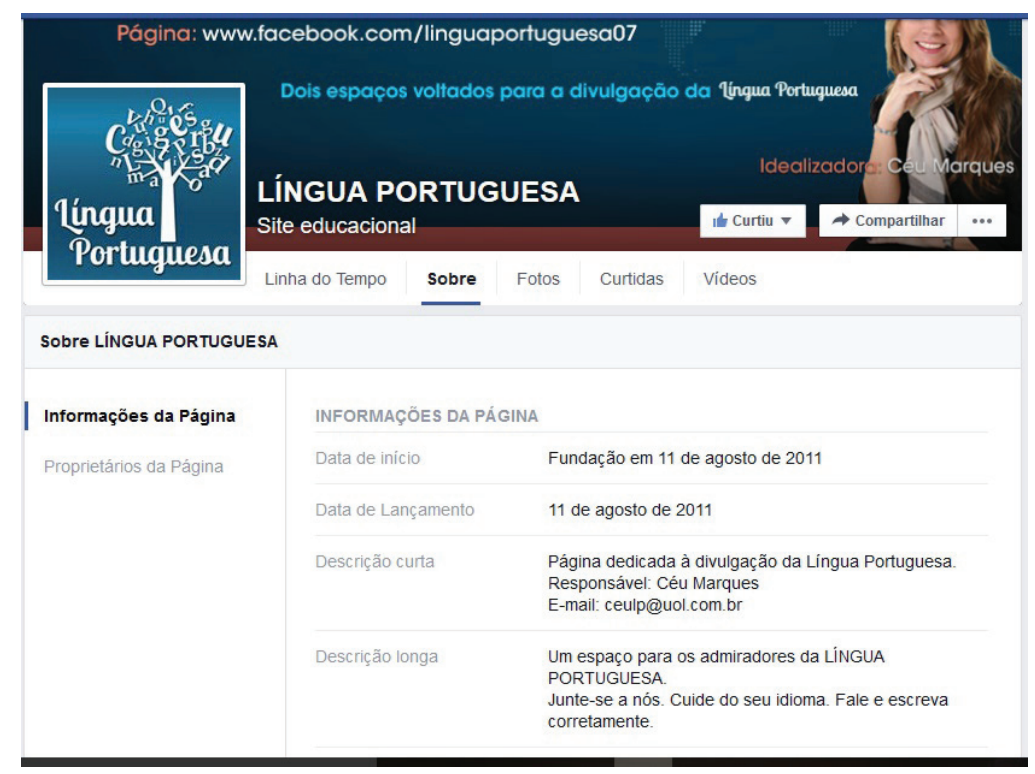

Figura 1: Apresentação da página

Fonte: Fanpage Língua Portuguesa (www.facebook.com)

A nosso ver, as ações que são desenvolvidas nessa página podem muito bem ser enquadradas como uma versão digital do que Bagno (1999) classifica como "comandos paragramaticais". Trata-se, nesse caso, de uma instância relativamente informal de ensino da língua portuguesa numa determinada perspectiva, paralelamente a instâncias formais como a escola.

Esses aspectos corroboram a relevância de investigações que se debruçam sobre a maneira como os fenômenos linguísticos são abordados em Lingua Portuguesa. Estudos sobre essa temática específica, bem como tendo por objeto essa fanpage, são ainda raros de acordo com o levantamento que fizemos. Como posto anteriormente, localizamos dois estudos anteriores ao nosso, dedicados à análise de postagens e comentários publicados na fanpage. A seguir, expomos brevemente as linhas gerais desses estudos, bem como as respectivas conclusões a que chegaram.

Pires e Pinto (2013) analisaram, sob uma perspectiva bakhtiniana, uma polêmica postagem (e os respectivos comentários) divulgada pela página no dia 19 de abril de 2012 com os seguintes dizeres: "Feliz Dia do Índio para você que fala: pra mim fazer!" Além dos aspectos linguísticos e enunciativos, o estudo ainda ressalta o preconceito étnico e social envolvido em associar a erro os usos 
do português brasileiro por indígenas. Os autores concentram seu interesse em analisar o dialogismo e os aspectos discursivos que constituem a postagem e a respectiva discussão na forma de comentários dos usuários da página Língua Portuguesa. De acordo com as conclusões de Pires e Pinto (2013, p. 54), "algumas vozes discursivas presentes no pôster [postagem] corroboram para perpetuar os preconceitos linguísticos, étnicos e sociais". Constata-se, portanto, uma multiplicidade de vozes por vezes em conflito principalmente enquadrando-se em dois polos que os autores identificam como "o conservadorismo linguístico e as vozes mais liberais". Em nossa própria análise, esse embate entre a tradição gramatical e a influência das ciências da linguagem também foi bastante visível, como se verá adiante.

Santos e Romano $(2015$, p. 1), por sua vez, realizaram estudo em que procuram constatar o preconceito linguístico veiculado pela fanpage Língua Portuguesa, evidenciando ainda o "autoritarismo" veiculado pelas postagens e pelos comentários dos seus seguidores. Os autores concluem que "o padrão de língua prescrito insistentemente pela página é essencialmente ideológico" uma vez que não se assenta em nenhum aspecto inerente à língua, mas sim à avaliação social de certos usos por certos falantes (SANTOS, ROMANO, 2015, p. 1). Conforme o estudo, a fanpage "constrói preconceitos e falsas ideias sobre o vernáculo de seus leitores" (SANTOS; ROMANO, 2015, p. 2), considerando que diversas postagens incorrem em flagrante reducionismo conceitual ao prescrever usos "corretos" norteados puramente pela gramática tradicional e ao tratar como equivalentes as noções de língua e de norma padrão. O foco desse estudo coincide em boa parte com o interesse central da presente pesquisa.

Em seguida, apresentamos nossa própria análise bem como os procedimentos que a orientaram.

\section{0 NORMATIVISMO LINGUÍSTICO NA FANPAGE LÍNGUA PORTUGUESA}

O presente estudo tem caráter exploratório e qualitativo, incluindo na análise tanto o texto/imagem que compõe a postagem na fanpage Língua Portuguesa como os comentários dos usuários. A análise de postagens e comentários selecionados é realizada de acordo com os seguintes critérios: (a) do ponto de vista do conteúdo, as postagens e comentários manifestam alguma forma de juízo sobre a língua em uso; (b) do ponto de vista de sua repercussão, obtiveram grande quantidade de "curtidas" (no mínimo 500) e comentários (no mínimo 50), além 
de uma incidência expressiva de "compartilhamentos". ${ }^{4}$ A diferença numérica entre curtidas e comentários reflete a postura da maioria dos usuários, que trata a primeira como uma forma de adesão mais imediata e menos exigente e talvez menos comprometedora do que o ato de comentar.

Ressalte-se ainda, no que diz respeito a possíveis implicações éticas, que o estudo se concentra em procedimentos de análise de texto e discurso, e não de informações ligadas a indivíduos específicos. Por outro lado, todos os textos analisados se caracterizam como postagens públicas pelo fato de se encontrarem em uma fanpage do Facebook, que ao contrário de outros espaços do site não admite restrição de acesso. As opções do usuário se limitam a "curtir" ou não "curtir" a página, mas o conteúdo desta é aberto ao público em qualquer caso, de modo que pode ser livremente acessado, discutido, copiado, "curtido", compartilhado e, portanto, analisado. Ao utilizar o material, tomamos apenas o cuidado de evitar a utilização de fotografias ou nomes de usuários, exceto quando se trata, eventualmente, de figuras públicas.

No exemplo exposto na Figura 2, a postagem traz a citação de um trecho de artigo de divulgação científica escrito pelo linguista Aldo Bizzocchi, em que o autor assume uma conexão entre gramática normativa e "língua padrão", contrapondo-a ao "português popular" . Conforme Bizzocchi, embora a gramática normativa seja "anacrônica, complicada, ilógica" e necessite "urgentemente ser repensada", isso não significa que o "português popular" deva ser alçado "à condição de língua padrão". Para um linguista, isso poderia parecer óbvio, mas aparentemente o texto do autor dialoga com alguma voz não explicitada que defenderia essa promoção do "português popular" à condição de "língua padrão". No que se segue, não discutimos o mérito da questão proposta pelo autor, mas apenas o teor dos comentários a título ilustrativo.

\footnotetext{
4 No universo do Facebook, as "curtidas" equivalem, em princípio, a uma apreciação positiva do conteúdo postado (o termo em inglês é like, "gostar"); os comentários tendem a funcionar como índice da repercussão positiva, mas também podem ser fruto de polêmicas instauradas pela postagem e pelos posicionamentos divergentes dos usuários; já os compartilhamentos indicam uma adesão ao conteúdo, por parte do usuário, a ponto de reproduzi-lo em sua "linha do tempo" pessoal. Apesar desse significado atribuído à ação de compartilhar, ela não foi objeto de interesse neste trabalho.

$5 \mathrm{O}$ texto completo pode ser lido no blog do autor (http://www.aldobizzocchi.com.br/artigo 125.asp), onde se informa que foi publicado no número 90 da revista Lingua Portuguesa em abril de 2013.
} 


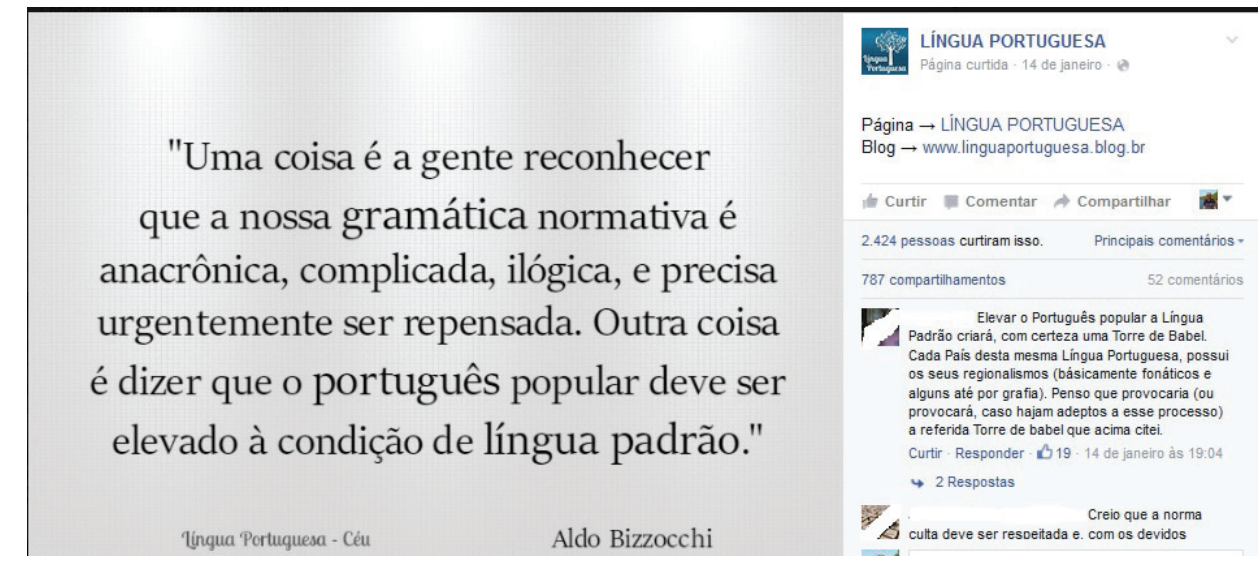

Figura 2: português popular x língua padrão

Fonte: Fanpage Língua Portuguesa (www.facebook.com)

Primeiramente, vale a pena salientar a postura da responsável pela página, que lança o texto para discussão abstendo-se de qualquer direcionamento para o debate. Essa postura, contudo, não indica uma eventual "neutralidade", e sim sugere que a postagem reflete o pensamento "oficial" da página, a julgar pela natureza dos debates que costumam ser travados nesse espaço. De modo geral, os autores dos 52 comentários feitos a essa postagem no espaço de dois dias ignoram a menção à gramática normativa e preferem se concentrar na questão de "elevar à condição de língua padrão" o português popular.

No comentário em destaque na Figura 2, aliás revelador de uma escrita bastante afastada da norma padrão, o usuário defende que a mencionada elevação do português popular ao status de padrão geraria "com certeza uma Torre de Babel". Embora não escreva em consonância com a "língua padrão", o que não o impede de fazê-lo e de ser compreendido, ao que se pode inferir o usuário acredita que o português popular tornaria impossível a compreensão entre os falantes, pois geraria a confusão a que faz referência o mito de Babel. Outra usuária, comentando a mesma postagem, faz uma avaliação de natureza diferente.

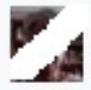

Se o nosso português popular for elevado à condição de língua padrão é melhor batizá-lo com qualquer outro nome que passe longe $\mathrm{da}$ bela língua portuguesa.

Curtir - Responder - B9 - 14 de janeiro às 20:22 
Para essa usuária, o "português popular" de alguma forma não merece o status de língua portuguesa. Ainda que esse português fosse eleito como "língua padrão", de acordo com a opinião da usuária, mesmo assim não poderia ser chamado pelo nome da "bela língua portuguesa". A "língua padrão", isto é, a norma padrão, orientada e regulada pela gramática normativa, seria a verdadeira língua portuguesa, caracterizada por ser "bela", ao contrário do "português popular" que certamente não possui tal beleza.

Temos, portanto, na postagem representada pela Figura 2 e nos respectivos comentários ilustrativos, alguns indícios de concepções inadequadas sobre a língua portuguesa. Sobre o "português popular", a concepção é a de que, por se afastar da gramática normativa, não possui beleza, não merece o nome de língua portuguesa e, se implantado como norma, instauraria uma espécie de caos comunicativo. A norma padrão, pelo contrário, é concebida como a verdadeira e "bela" língua portuguesa, a única capaz de permitir a superação do caos na comunicação.
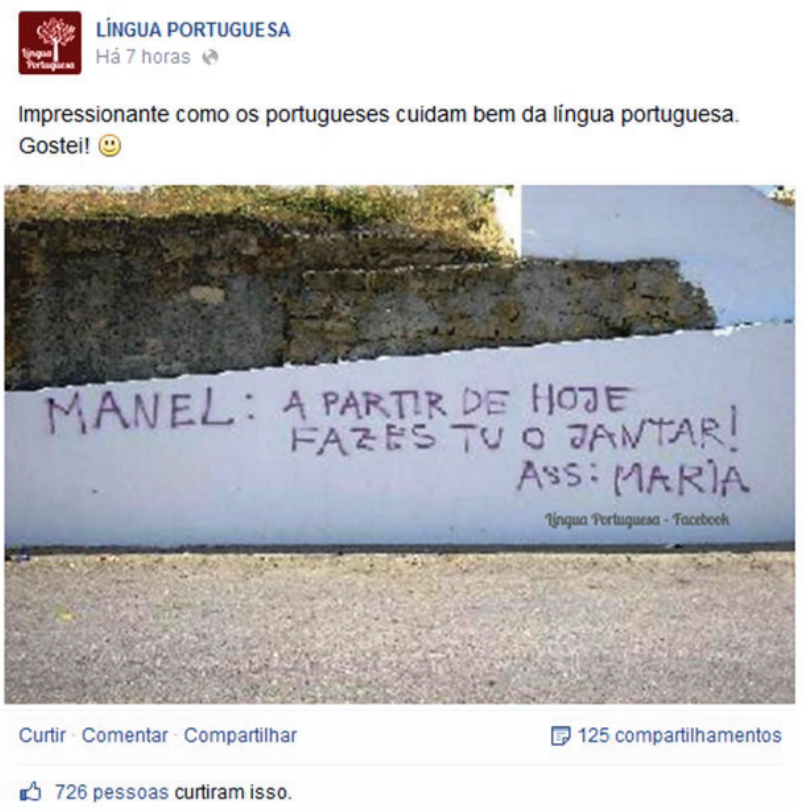

Figura 3: Português bom é o de Portugal Fonte: Língua Portuguesa (www.facebook.com)

A postagem representada pela Figura 3 exemplifica um caso em que a responsável pela fanpage assume explicitamente um juízo de valor sobre o conteúdo. 
De acordo com ela, o texto pichado no muro evidencia "como os portugueses cuidam bem da língua portuguesa". A professora qualifica esse cuidado como "impressionante" e afirma que gostou disso (o equivalente a uma "curtida" no universo do Facebook). Chama a atenção ainda o uso de um emoticon (smiley) com a carinha feliz reforçando o enunciado verbal "Gostei!". Esse uso sinalizaria uma adesão parcial ou relativa a recursos comunicativos típicos da Internet e das redes sociais digitais, pois, como veremos adiante, estas são frequentemente responsabilizadas por manifestar usos contrários ao "cuidado com a língua".

Especificamente, a temática da postagem recupera o velho mito de que o verdadeiro ou o melhor português é aquele escrito e falado em Portugal, conforme discutido por Bagno (1999). Aparentemente, o que fundamenta o juízo positivo sobre a escrita lusitana é a utilização da forma verbal na segunda pessoa do singular, uma forma por sua vez claramente em desuso no português brasileiro. Essa diferença de usos, facilmente explicável pela admissão de diferentes variedades linguísticas em uma mesma língua, é tratada como ilegítima e o que se pressupõe é que os falantes do português brasileiro seriam menos cuidadosos com o idioma por não falarem ou escreverem como os portugueses. O português europeu, nesse caso, seria tomado como a norma padrão para o português brasileiro, um absurdo incomensurável do ponto de vista científico.

Os comentários, por sua vez, manifestam uma autoestima linguística em crise ou ainda o chamado complexo de vira-latas que de acordo com o senso comum é alimentado por muitos brasileiros, ou seja, bom é tudo aquilo que é feito no exterior e ruim tudo que é nacional. Implícito no comentário de que no Brasil seria "apartir de hoji, cê fais a janta" está a ideia de que os falantes brasileiros não mostram qualquer cuidado com a língua. Noutras palavras, a representação grosseira do que seria o enunciado em uma variedade linguística popular, hipoteticamente inscrita em um eventual muro brasileiro, evidenciaria a falta de cuidado com a língua e não outros motivos como a ausência de acesso digno e adequado à educação linguística na escrita oficial, por exemplo.

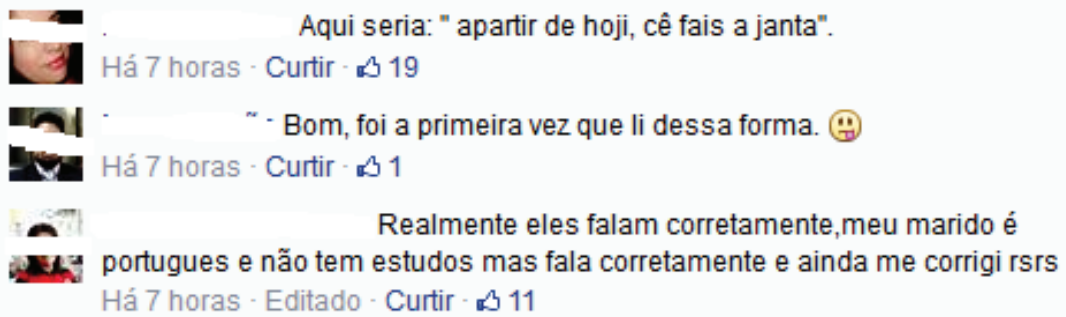


De outro comentário, depreende-se que o imaginário negativo sobre os usos dos falantes brasileiros, em contraposição aos dos portugueses, é poderoso a ponto de fazer a usuária aceitar que o marido, mesmo "sem estudos", tem autoridade para corrigi-la, pois "fala corretamente". Aparentemente, tal autoridade decorre simples e automaticamente do fato de ser um falante do português de Portugal.

A concepção de língua subjacente às ideias construídas em torno dos usos do português por falantes lusitanos, conforme expressa no âmbito da página Língua Portuguesa, remete a um estágio pré-científico e particularmente pré-sociolinguístico: a língua é uma entidade monolítica, dotada de um padrão, diante do qual tudo o mais deve ser tratado como desvio ou, nos termos da postagem e dos comentários, como falta de cuidado com o idioma.

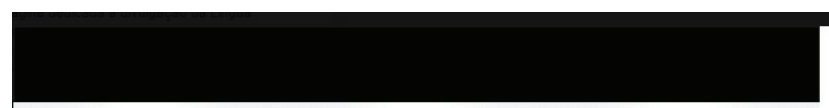

Verbo no infinitivo vem perdendo o "R" nas redes sociais

Lingua Portuguesa - Céu

Errado: Vou toma banho. Quero escreve uma carta. Vou fala com você. Irei arruma o quarto agora.

Certo: Vou tomar banho. Quero escrever uma carta. Vou falar com você. Irei arrumar o quarto agora.

A marca do verbo no infinitivo é justamente o -r final. Não o retire ao escrever.
LÍNGUA PORTUGUESA

Página curtida - 22 de dezembro - e

Página $\rightarrow$ LINGUA PORTUGUESA Blog $\rightarrow$ www.linguaportuguesa.blog.br

Ite Curtir In Comentar $A$ Compartilhar $[$. 1.236 pessoas curtiram isso. Principais comentários. 1.155 compartihamentos 47 comentários

Tenho $o$ infeliz defeito $d$ me indignar demais ao assistir,ouvir noticiários da manhã, É vergonhoso e revoltante ouvir a equipe da GLOBO a começar pelo Rodrigo além d péssima dicção. nada de pronunciar o $R$ no final dos verbos: "aenti vai falá... vai mostrá ... né... cumé qui tá", bem com as jornalistas... cumé.... Até jornalistas mais famosos caem nestes erros. SERA Q A GLOBO NAO TEM ALGUEM COMPETENTE PARA OS ORIENTAR? De que adianta a beleza, boa aparência, com tantos erros... Curtir-Responder - $B_{3} \cdot 22$ de dezembro às 23:28

Figura 4: Infinitivo nas redes sociais

Fonte: Língua Portuguesa (www.facebook.com)

Ocasionalmente, conforme a Figura 4, o normativismo linguístico imbuído do "cuidado com a língua" pode eleger um bode expiatório para os "erros" de português cometidos pelos brasileiros: trata-se das redes sociais (digitais), a quem é atribuída a responsabilidade por fenômenos que, na verdade, se não são categóricos, são pelo menos muito comuns no português brasileiro, independentemente da Internet. Tal é o caso do infinitivo verbal que "vem perdendo o ' $\mathrm{R}$ ", , mas não apenas "nas redes sociais" como defende a fanpage. Parece claro que a "perda" em questão primeiramente se manifesta como um fenômeno da fala tanto popular como culta no português brasileiro, em que o fonema correspondente não é pronunciado. Em segundo lugar, o fenômeno se mostra igualmente em práticas de escrita não padrão, influenciadas pela fala, podendo envolver tanto falantes adultos com deficiências 
na aprendizagem dessa escrita como crianças, adolescentes e jovens em processo de escolarização. Se as redes sociais digitais têm algum papel nessa questão, tratase apenas de dar maior visibilidade ao fenômeno e não de funcionar como a sua causa. Por meio da postagem, consequentemente, a fanpage propõe uma questão equivocada para os seus usuários. Isso fica claro até pelo fato de que os exemplos mostrados não provêm das citadas redes, mas, em um procedimento típico das posturas normativistas, são frases elaboradas pela própria página e não instâncias de uso real da língua.

O fato de que se trata de um fenômeno da fala primordialmente e não da escrita se impõe no comentário exibido ao lado da postagem. O usuário da página tem como foco a pronúncia de jornalistas da televisão que, na sua opinião, além de outros problemas de dicção, cometem o erro de "não pronunciar o R no final dos verbos". No comentário, ressaltem-se as reações do usuário que se diz indignado e qualifica as pronúncias que critica como vergonhosas e revoltantes. Nessa concepção, tanto da fanpage como do usuário, a língua deve ser vista como uma entidade estática, orientada por um padrão escrito ao qual a fala deve se submeter e o qual deve reproduzir. Dessa forma, a fala deveria funcionar como representação da escrita, em uma concepção absolutamente insustentável de acordo com os estudos especializados. $^{6}$
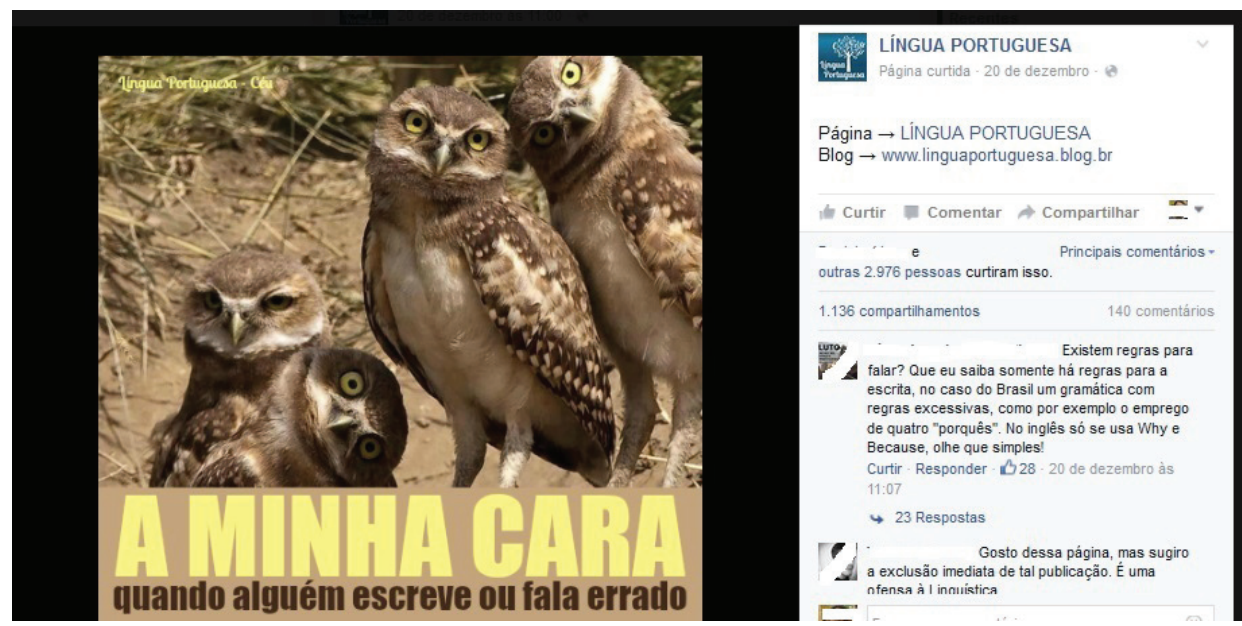

Figura 5: Escrever ou falar errado

Fonte: Língua Portuguesa (www.facebook.com) 
Nesta postagem (Figura 5), a página Língua Portuguesa assume claramente a postura normativista de recriminar usos tidos como errados na fala e na escrita. No texto, a imagem das corujas que simula um olhar arregalado encarando o interlocutor, ao lado do enunciado "A MINHA CARA quando alguém escreve ou fala errado", com destaque para a expressão "a minha cara", deixa subentendida uma condenação a práticas letradas ou faladas que não se enquadram no padrão. Mais uma vez, a fanpage ignora qualquer noção das ciências da linguagem sobre os usos da língua e se mantém alinhada com a tradição normativa segundo a qual esses usos se dividem em certo e errado e ponto final.

Com esse exemplo, e ao nos voltarmos para os comentários, gostaríamos de ressaltar duas questões que nos parecem bastante relevantes. Em primeiro lugar, lamentamos que uma página autodefinida como "site educacional" seja utilizada para perpetuar velhos mitos e preconceitos sobre a língua portuguesa ao invés de contribuir para a educação linguística de seus usuários. $\mathrm{O}$ autor do primeiro comentário (vide Figura 5) questiona: "Existem regras para falar? Que eu sabia somente há regras para a escrita". Diante desse questionamento, um posicionamento condizente com as ciências da linguagem afirmaria que todo uso da língua, falado ou escrito, culto ou popular, só pode ser dotado de regras, de gramática, pois sem isso não haveria possibilidade de interação por meio da linguagem verbal. Posicionamentos dessa natureza representariam uma significativa contribuição para desfazer as concepções inadequadas que os usuários manifestam sobre a língua. Mas não é o que se encontra na página Língua Portuguesa, pelo menos não da parte de sua proprietária.

Em segundo lugar, um aspecto importante, embora não pareça ter uma força expressiva nos debates travados na página, é exatamente a manifestação de usuários que chamam a atenção para as contribuições das ciências da linguagem, frequentemente corrigindo não só a própria página, mas corrigindo-se entre si. Diante da postagem representada pela Figura 5, por exemplo, um dos usuários sugere "a imediata exclusão de tal publicação" por ser uma "ofensa à Linguística". Embora tais observações pareçam ser totalmente ignoradas pela responsável pela página, acreditamos que possam contribuir para discussões mais equilibradas sobre as questões linguísticas, do ponto de vista dos usuários.

Como presumivelmente parte dos usuários do Facebook que seguem a fanpage tem formação em Letras e, portanto, contato com a linguística, essas vozes representativas das ciências da linguagem acabam se manifestando nas diversas discussões encetadas nesse ambiente. No comentário abaixo, publicado com referência à postagem contida na Figura 2, que criticava a possibilidade de o 
português popular ser elevado à condição de "língua padrão", o usuário lamenta essa distinção entre "mais ou menos elevada" considerando que no país "todos falam a mesma língua". Embora não faça nenhuma referência à linguística em geral ou à sociolinguística em particular, esse posicionamento é coerente com a concepção de língua sustentada por essas ciências.

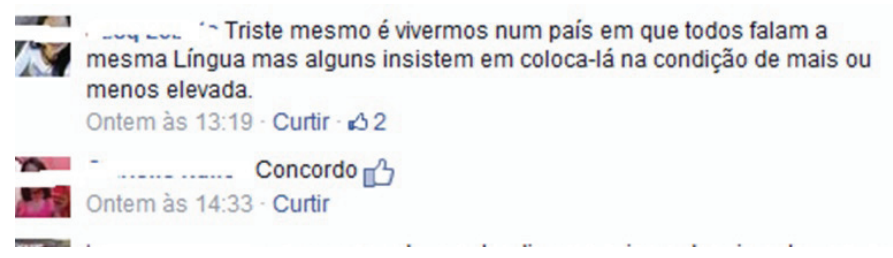

Da mesma forma, os comentários abaixo, relativos à discussão sobre o cuidado dos portugueses com a língua (Figura 3), opõem-se ao posicionamento da fanpage e dos demais usuários apelando para fundamentos das ciências da linguagem.

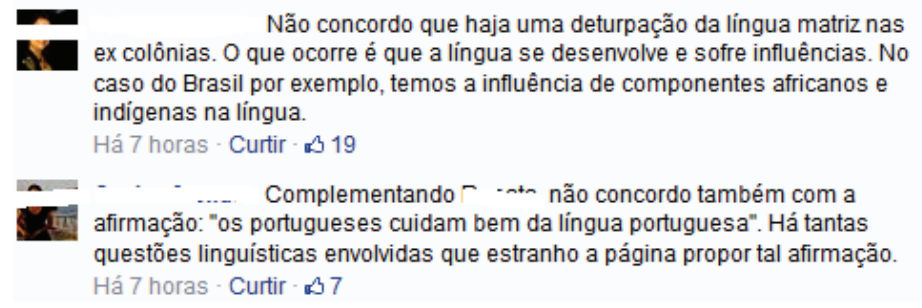

No primeiro caso, o autor evita tratar como "deturpação" as influências dos "componentes africanos e indígenas na língua", responsáveis, segundo ele, pelas diferenças entre o português brasileiro e o europeu (de Portugal). Dessa forma, levanta-se contra a tese da fanpage de que os portugueses seriam cuidadosos com a língua, ao contrário dos brasileiros. No comentário seguinte, o usuário assume esse ponto de vista explicitamente, mas vai além, criticando a página por "propor tal afirmação" quando haveria tantas questões linguísticas envolvidas. Posto de outra forma, entendemos que o posicionamento desse usuário vem ao encontro do nosso quando ponderamos que o espaço da fanpage poderia ser utilizado de forma bem mais produtiva do ponto de vista da educação linguística de seus usuários, ao invés de propor discussões que nada mais fazem do que contribuir para perpetuar concepções inadequadas e inexatas sobre a língua portuguesa da qual, aliás, se propõe cuidar. 


\section{CONSIDERAÇÕES FINAIS}

Com a finalidade de contribuir para a reflexão contínua sobre a natureza da língua e da linguagem, inclusive consideradas do ponto de vista dos seus usos em ambiente virtual, procuramos neste trabalho analisar uma pequena amostra de postagens e comentários em uma página do Facebook destinada à "divulgação" e ao "cuidado" com a língua portuguesa. Ao eleger como objeto de estudo o normativismo contido nas concepções de língua/linguagem expressas no âmbito da fanpage Lingua Portuguesa, "site educacional" com quase um milhão e meio de seguidores, criada e alimentada por uma professora de português, procurávamos contribuir para compreender o funcionamento, a repercussão e as concepções desse tipo de instrumento regulador dos usos da língua através das redes sociais digitais.

Observamos que o normativismo linguístico nas redes sociais digitais, exemplificadas pelo Facebook, opera em páginas como Lingua Portuguesa no sentido de manter e reforçar velhas concepções de língua/linguagem alinhadas com a tradição gramatical. De um modo geral, pode-se afirmar que a língua é, nesse contexto, identificada com a norma padrão, a ponto de ser designada como "língua padrão". Essa variedade idealizada, portanto, é tomada como a língua legítima, e o "português popular" é tratado como algo menor cuja legitimidade no máximo será relegada à oralidade.

Em consonância com isso, a língua também é concebida segundo um referencial estético: o padrão é belo, o não padrão é feio. Por isso, o "português popular" não mereceria o nome da "bela língua portuguesa". De um ponto de vista qualitativo, segundo a metáfora conceitual BOM É PARA CIMA, RUIM É PARA BAIXO (LAKOFF; JOHNSON, 2002) atualizada em uma das postagens, o "português popular" é baixo, a "língua padrão" é elevada. Esses usos "belos" e "elevados" podem ser, de acordo com a fanpage e seus usuários, atribuídos à variedade lusitana, tomada, em um contexto mais amplo, como a verdadeira e legítima norma para a língua portuguesa.

Devido à intensidade das práticas interacionais desenvolvidas no ambiente virtual e particularmente por intermédio dos sites de redes sociais, nas quais se engajam democraticamente pessoas de variados backgrounds, com uma forte incidência de adolescentes e jovens, com ou sem habilidade para escrever dentro do padrão (orto) gráfico da língua, também não tardou para que essas redes fossem responsabilizadas por todo e qualquer problema de escrita por mais comum e generalizado que seja. Em nossa análise, vimos que as redes sociais digitais são responsabilizadas inclusive 
por fenômenos cuja origem situa-se claramente na oralidade, como a escrita de infinitivos verbais sem o " $\mathrm{r}$ " final.

A partir dessas observações, percebemos como alguns dos usuários se voltam contra as discussões travadas na página, por conceberem, auxiliados por concepções de língua/linguagem advindas dos estudos especializados da área, que aquelas discussões poderiam ser bem mais exatas e muito mais produtivas se fossem orientadas pelo saber científico das ciências da linguagem.

Nesse sentido, concluímos que as velhas instâncias de normatização da língua/ linguagem encontram, no ambiente virtual das redes sociais digitais, novas formas de sobrevivência em instrumentos como as fanpages do Facebook, por meio das quais buscam reagir ao dinamismo dos usos da linguagem manifestos de forma muito mais intensa na Internet do que poderiam sê-lo nos suportes convencionais de escrita. Por um lado, a adesão dos usuários em geral a essas instâncias normatizadoras que simplesmente reproduzem velhos preconceitos é quase automática, uma vez que as pessoas são seduzidas com facilidade inclusive por "dicas" de uso da língua que aparentam muito conhecimento e por definições de palavras eruditas embora de utilização pouco provável no cotidiano da maioria. Por outro lado, talvez as vozes representativas das ciências da linguagem ainda se façam pouco representadas nesse âmbito, talvez ainda não tenham tentado chegar às pessoas não familiarizadas com a área de modo acessível e relevante, buscando esclarecê-las sobre as questões mais urgentes no que diz respeito à língua e seus usos.

Enquanto isso, será difícil mensurar o desserviço prestado por páginas como Lingua Portuguesa para uma compreensão adequada da língua pelos seus usuários. O estudo aqui apresentado pretende ser apenas uma amostra das questões a investigar e dos aspectos a observar e discutir. As facetas do normativismo linguístico nas redes sociais digitais com certeza são bem mais complexas e múltiplas e permanecem como um convite à pesquisa fundamentada em concepções de língua/linguagem adequadas.

\section{REFERÊNCIAS BIBLIOGRÁFICAS}

BAGNO, M. (1999). Preconceito linguístico: o que é, como se faz. São Paulo: Loyola.

BAGNO, M. (2003). A norma oculta: língua \& poder na sociedade brasileira. São Paulo: Parábola.

BAGNO, M. (2007). Nada na língua épor acaso: por uma pedagogia da variação linguística. São Paulo: Parábola. 
BAGNO, M. (2011). O que é uma língua? Imaginário, ciência e hipótese. In: LAGARES, X. C.; BAGNO, M. (Orgs.). Políticas da norma e conflitos linguísticos. São Paulo: Parábola. p. 355-387.

BAGNO, M. (2013). Sete erros aos quatro ventos: a variação linguística no ensino de português. São Paulo: Parábola.

BARROS, E. F. A. (2015). A construção da escrita colaborativa e argumentação em textos no Facebook. 2015. 110 f. Dissertação (Mestrado em Linguística) - Universidade Federal de Pernambuco, Recife.

BEZERRA, Benedito G. (2013). O discurso acadêmico sobre língua e linguagem na internet. In: SIMPÓSIO HIPERTEXTO E TECNOLOGIAS NA EDUCAÇÃO, 5./ COLÓQUIO INTERNACIONAL DE EDUCAÇÃO COM TECNOLOGIAS, 1., 2013, Recife. Anais Eletrônicos. Recife, NEHTE/UFPE. p. 1-20.

BISOGNIN, T. R. (2009). Sem medo do internetês. Porto Alegre: AGE.

FARACO, C. A. (2008). Norma culta brasileira: desatando alguns nós. São Paulo: Parábola.

ILARI, R.; BASSO, R. (Org.). (2006). O português da gente: a língua que estudamos a língua que falamos. São Paulo: Contexto.

LAKOFF, G.; JOHNSON, M. (Org.). (2002). Metáforas da vida cotidiana. Campinas, SP: Mercado de Letras; São Paulo: Educ.

LIMA NETO, V. (2014). Um estudo da emergência de gêneros no Facebook.. 2014. 313 f. Tese (Doutorado em Linguística) - Universidade Federal do Ceará, Fortaleza.

MARCUSCHI, L. A. (2008). Produção textual, análise de gêneros e compreensão. São Paulo: Parábola. MARCUSCHI, L. A. (2001). Da fala para a escrita: atividades de retextualização. 2. ed. São Paulo: Cortez.

MELO, Simone Pereira de; BEZERRA, Benedito G. (2011). O internetês em questão: "português assinado a tecladas"? In: BEZERRA, Benedito G. (Org.). Leitura e escrita na interação virtual. Recife: EDUPE. p. 27-43.

MILROY, J. (2011). Ideologias linguísticas e as consequências da padronização. In: LAGARES, X. C.; BAGNO, M. (orgs.). Politicas da norma e conflitos linguísticos. São Paulo: Parábola Editorial. p. 49-85.

PIMENTEL, Renato L. (2014). Um estudo sobre bibridização e agrupamento de gêneros no Facebook. 2014. Dissertação (Mestrado em Linguística) - Universidade Federal de Pernambuco, Recife.

PIRES, C. H. de S.; PINTO, D. dos S. (2013). As diferentes vozes e os múltiplos sentidos em publicação da página "Língua Portuguesa" no Facebook. EID\&A, Ilhéus, n. 4, p. 42-55, dez. 2013. Disponível em: < http://periodicos.uesc.br/index.php/eidea/article/view/430/436> Acesso em 17 jan. 2016.

RECUERO, R. (2009). Redes sociais na internet. Porto Alegre: Sulina.

SANTOS, A. P.; ROMANO, V. P. (2015). Preconceito linguístico: Facebook \& prescritivismo. Revista Científica da FEPI, v. 6, n. 1, p. 1-2. Disponível em: < http://www.fepi.br/revista/ index.php/revista/article/view/314/172> Acesso em: 20 dez. 2015. 
Normativismo linguístico em redes sociais digitais...

SWALES, J. M. (2009). Repensando gêneros: nova abordagem ao conceito de comunidade discursiva. In: BEZERRA, Benedito G.; BIASI-RODRIGUES, Bernardete; CAVALCANTE, Mônica Magalhães (Orgs.). Gêneros e sequências textuais. Recife: EDUPE. p. 197-220.

SWALES, J. M. (1990). Genre analysis: English in academic and research settings. Cambridge: Cambridge University Press, 1990.

Recebido: 02/07/2016

Aceito: 22/09/2016 